\title{
Synthesis, characterization, and anti-fouling properties of cellulose acetate/polyethylene glycol-grafted nanodiamond nanocomposite membranes for humic acid removal from contaminated water
}

\author{
Habib Etemadi ${ }^{1,2} \cdot$ Reza Yegani $^{1,2} \cdot$ Mahdi Seyfollahi $^{1,2} \cdot$ Mahyar Rabiee $^{1,2}$ \\ Received: 11 September 2017 / Accepted: 6 February 2018 / Published online: 21 April 2018 \\ (c) The Author(s) 2018
}

\begin{abstract}
Polyethylene glycol-grafted nanodiamond (ND-PEG) was synthesized from pristine detonation NDs and utilized to prepare novel cellulose acetate/polyethylene glycol-grafted nanodiamond(CA/ND-PEG)nanocomposite membranes. Due to unique thermal, mechanical, and antibacterial properties and very easy cleaning of fouled ND-embedded CA nanocomposite membranes, we tried to investigate the performance of CA/ND-PEG membrane for humic acid (HA) removal from contaminated water. Surface functionalization was confirmed by Fourier transform infrared spectroscopy and thermogravimetry analysis. Pristine and functionalized ND with different concentration was added in the casting solution containing CA. The prepared membranes were characterized using contact angle, mechanical strength, scanning electron microscopy (SEM), transmission electron microscopy, and permeation tests. SEM micrographs of the surface of the membranes depicted the increase in the number of pores by the addition of ND and especially ND-PEG into polymer matrix. The results indicated that the nanocomposite membrane with $0.5 \mathrm{wt} \%$ ND-PEG exhibited excellent hydrophilicity, mechanical properties, permeability, high rejection, high abrasion resistance, and good anti-fouling performance. The HA adsorption on the membrane surface decreased from 2.85 to $2.15 \mathrm{mg} \mathrm{cm}^{-2}$ when the ND-PEG content increased from 0 to $0.5 \mathrm{wt} \%$. Most importantly, the HA filtration experiments revealed that the incorporation of ND and especially ND-PEG particles reduced membrane irreversible fouling, dramatically. Meanwhile, the analysis of the fouling mechanism based on Hermia's model revealed that cake formation is a prevailing mechanism for all membranes.
\end{abstract}

Keywords Nanodiamond $\cdot$ Polyethylene glycol $\cdot$ Cellulose acetate $\cdot$ Nanocomposite membrane $\cdot$ Anti-fouling

\section{Introduction}

Membrane technology is widely used for water treatment and has obtained more attention than any other separation process due to low energy consumption, easy scale-up, less or no use of chemicals and no harmful by-product formation [1]. Humic acid (HA), an important component of natural organic matters (NOMs), is derived from the decomposition of the plant and animal materials that are commonly found in surface and ground water and strictly affect the taste and

Reza Yegani

ryegani@sut.ac.ir

1 Faculty of Chemical Engineering, Sahand University of Technology, Tabriz, Iran

2 Membrane Technology Research Center, Sahand University of Technology, Tabriz, Iran color of water [2-4]. Therefore, the removal of NOMs is extremely important and has become a challenging subject of research in the current development of water purification technologies.

Cellulose acetate (CA) is one of the foremost among ultrafiltration (UF) polymer membranes. It has been widely used in separation processes, due to its high hydrophilicity, high biocompatibility, good desalting, non-toxic nature, performance high potential flux, and relatively low cost [4-6]. However, this membrane usually contains a dense skin layer and a low porous sub-layer, which result in an extremely low flux [7]. On the other hand, one of the serious problems arising during UF membrane filtration is membrane fouling by NOMs [8]. Membrane fouling can be classified as reversible fouling (which can be eliminated by physical cleaning) and irreversible fouling (which cannot be entirely counteracted by physical cleaning and typically requiring chemical 
cleaning) [9]. Hence, to improve the performance of CA membranes, modification of polymer seems to be essential.

Recently, nanocomposite membranes have been applied in membrane technology for the removal of pollutants from water to wastewater [10]. Polymer nanocomposite membranes are formed by incorporation of nanoparticles into polymer matrix. In many cases, a significant improvement in mechanical, thermal, antibacterial, and anti-fouling properties has been achieved [11, 12]. However, the well dispersion of nanoparticles is still a challenging subject for researchers.

Carbon-based nanomaterials are potentially useful due to their unique physical and chemical properties. Among them, nanodiamond (ND) particles with a diamond core $\left(\mathrm{sp}^{3} \mathrm{car}-\right.$ bon-carbon bond) that is covered with multiple functional groups $[13,14]$ are of great interest. Due to interesting characteristics such as hydrophilicity [15, 16], antibacterial activity $[12,17,18]$, biocompatibility $[19,20]$, chemical stability [19], thermal stability [20] non-toxicity [19-21], superior hardness and mechanical properties, resistance to harsh environments [19], and ease of surface functionalization [20], ND particles have been nominated as reinforcement fillers in the fabrication of nanocomposite materials.

Despite the advantages described above, pristine ND particles usually form micro-sized agglomerates [22]. The presence of carbon impurities among the ND particles and consequently agglomeration of ND particles led to poor dispersibility and weak interfacial interactions with polymer matrix [22, 23]. Thus, surface functionalization is an essential method to reduce the aggregation of nanoparticles and improve their performance.

According to our previous findings, polyethylene glycol (PEG) embedded polyolefin membranes showed excellent hydrophilic properties and exhibited great anti-fouling performance [11]. PEG can enhance biological properties including high biocompatibility, weak interactions with protein, and antibacterial properties [24]. It is used as a head group in nonionic surfactants to cover surfaces to prevent proteins and hydrophobic foulants in surface water to adhere to the membrane surface [25]. In other words, PEG produces a high degree of steric exclusion and entropy at PEG-water interfaces due to the formation of hydrogen bond with water molecules, which in turn results in protein repellency [11, 26]. The conjugated PEG chains on the nanoparticle surface could reduce protein interactions with the nanoparticles and consequently with the membrane surface [27]. According to Wang et al. [24] and as well as Zhang et al. [28], PEGylated ND can improve dispersion and reduce interaction with proteins. In addition, a literature survey showed that PEG is an ideal polymer for the modification of nanostructured materials to be used in polymeric membranes [11, 28, 29].

To combine the great mechanical and thermal properties of ND particle-embedded CA membranes [12] with excellent anti-fouling performance of PEG containing polyolefin membranes [11] in the current study, PEG-grafted ND particles were employed to fabricate ND-embedded CA nanocomposite membrane. As reported in the literature, nanocomposite membranes such as $\mathrm{HDPE} / \mathrm{SiO}_{2}$ [11], polyethersulfone (PES)/ Stöber silica [30], CA/organically modified montmorillonite [7], polyamide (PA)/multi-wall carbon nanotube (MWCNT) [31], polysulfone/GO-TiO 2 [9], and $\mathrm{PVDF} / \mathrm{TiO}_{2}$ [32] enhanced the performance of polymeric membranes in HA removal from contaminated water. In our previous work, pristine and carboxylated ND particles, i.e., ND and ND-COOH were added to the CA polymer to investigate the anti-fouling properties of the prepared nanocomposite CA membranes in HA removal from contaminated water [33]. Obtained results were promising; however, anti-fouling properties were far from our preliminary goal. It was concluded that more modified ND particles were required.

In this work, due to the great performance of PEGylated NPs [11, 34], the anti-fouling properties of nanocomposite CA membranes containing PEGylated ND particles were compared by CA-ND membranes during the filtration of HA. Nanocomposite membrane was synthesized using blending method followed by phase inversion process using pristine and PEG-grafted ND particles denoted as ND and ND-PEG, respectively. Several structural and operational analyses were carried out to identify enhancement in membrane surface hydrophilicity, abrasion resistance, and anti-fouling properties during the filtration of HA. The fouling mechanisms of the fabricated membranes were also analyzed using classical Hermia model.

\section{Theory of fouling mechanism}

To identify the possible dominant mechanism of the membrane fouling under constant filtration pressure, Hermia models were used. These models are written in a common mathematical form as follows [35]:

$\frac{\mathrm{d}^{2} t}{\mathrm{~d} V^{2}}=k\left(\frac{\mathrm{d} t}{\mathrm{~d} V}\right)^{m}$

where $t$ is the filtration time, $V$ is the filtrate volume, $k$ is the resistance coefficient, and $m$ is a constant which characterizes the fouling model. The permeate flux $(J)$ is expressed as follows [36]:

$J=\frac{1}{A} \frac{\mathrm{d} V}{\mathrm{~d} t}$.

Equation (1) can be written as follows:

$\frac{\mathrm{d} J}{d t}=-\mathrm{kA}^{2-m} J^{3-m}$.

According to this model, there are four fouling mechanisms. In the complete pore blockage mode, under condition, 
it is assumed that no particles are situated on top of other particles or on membrane surface. The model was derived by substituting $m=2$ in Eq (3) and integrating with regard to the time of permeate flux, Eq (4) can be obtained [37, 38]:

$\ln \left(\frac{1}{J}\right)=\ln \left(\frac{1}{J_{0}}\right)+K_{\mathrm{b}} t$

where $K_{\mathrm{b}}$ and $J_{0}$ are complete pore blocking coefficient and pure water flux, respectively.

The internal pore blocking mode accounts for fouling that occurs in the internal structure of the membrane. Internal pore blocking is due to the constriction of membrane pores caused by small particles attached into pore walls. The exponent is put with the value of $m=1.5$ and integrating Eq (3), the permeate flux is decreased and is related to time using the following equation [37, 39]:

$\frac{1}{\sqrt{J}}=\frac{1}{\sqrt{J_{0}}}+K_{\mathrm{s}} t$

where $K_{\mathrm{s}}$ is an internal pore blocking coefficient.

The intermediate pore blockage mode is similar to the complete pore blockage model, in addition to accounting for the possibility of particles bridging a pore by obstructing the entrance without completely blocking it [40]. This model substitutes $m=1 \mathrm{in} \mathrm{Eq}$ (3), and by integrating, the following equation is obtained [41]:

$\frac{1}{J}=\frac{1}{J_{0}}+K_{\mathrm{i}} t$

where $K_{\mathrm{i}}$ is an intermediate pore blocking coefficient.

In the case of cake formation, particles do not participate in changes in membrane pores. A cake layer is formed outside the external membrane and increases hydraulic resistance. The cake filtration model was obtained by substituting the value of $m=0$ and integrating Eq (3), the obtained equation is expressed as follows [42]:

$\frac{1}{J^{2}}=\frac{1}{J_{0}^{2}}+K_{\mathrm{c}} t$

where $K_{\mathrm{c}}$ is a cake pore blocking coefficient.

\section{Experimental}

\section{Materials}

Cellulose acetate $\left(M_{\mathrm{n}}=30,000\right)$ was used as polymer material to prepare the CA membrane, supplied by SigmaAldrich (Germany). The detonation ND nanoparticle procured from Nabond Technology Co., Ltd., China, with phase purity higher than $98 \%$, an average diameter of $5 \mathrm{~nm}$ and a specific surface area of $282.8 \mathrm{~m}^{2} \mathrm{~g}^{-1}$, was used as nanoparticle. $N-N$-dimethylformamide (DMF, 99.8\%) was purchased from Merck (Germany) and used as a solvent to prepare dope solution. Deionized (DI) water was used as the nonsolvent. PEG $\left(M_{\mathrm{W}}=200 \mathrm{~g} \mathrm{~mol}^{-1}\right)$ and 1,3-phenylenediamine (mPDA) as hydrophilic modifiers were purchased from Sigma-Aldrich. Thionyl chloride $\left(\mathrm{SOCl}_{2}\right)$, triethylamine, and tetrahydrofuran (THF) were obtained from Merck.

\section{PEG-grafted ND nanoparticles}

According to the literature [22], to remove the organic impurities and create carboxylic functional groups on the ND nanoparticles surface (denoted by ND-COOH), pristine detonation NDs were dried at $80{ }^{\circ} \mathrm{C}$ for $2 \mathrm{~h}$ in a vacuum dryer and the process was continued by oxidation in air at a temperature between 430 and $450{ }^{\circ} \mathrm{C}$ for $1.5 \mathrm{~h}$. PEG-grafted ND nanoparticles were synthesized according to the method described by Wang et al. [24]. A sample of ND-COOH nanoparticles $(50.26 \mathrm{mg})$ was dried in a vacuum oven at $70{ }^{\circ} \mathrm{C}$ overnight and then suspended in $2 \mathrm{~mL}$ anhydrous DMF in an ultrasonic bath. The prepared suspension was immediately added to $20 \mathrm{~mL} \mathrm{SOCl}{ }_{2}$ and refluxed for $24 \mathrm{~h}$ at $70{ }^{\circ} \mathrm{C}$ to convert the carboxylic acids to acyl chlorides (denoted by ND-COCL). The mixture was evaporated with a rotary evaporator to remove excess $\mathrm{SOCl}_{2}$ at $40{ }^{\circ} \mathrm{C}$. After adding $20 \mathrm{~mL}$ anhydrous DMF, $50.48 \mathrm{mg}$ PEG, and $2 \mathrm{~mL}$ triethylamine, the mixture was refluxed for $24 \mathrm{~h}$ at $90{ }^{\circ} \mathrm{C}$, separated by centrifugation, and washed with methanol and distilled water five times to remove excess PEG. The obtained powder was dried under vacuum at $60^{\circ} \mathrm{C}$, overnight.

\section{Membrane preparation}

The neat and nanocomposite CA membrane flat sheets were prepared by phase inversion via immersion precipitation technique. The blend homogeneous solutions were prepared by dissolving the $17.5 \mathrm{wt} \%$ of CA polymer in DMF as a solvent with different concentrations of ND, and ND-PEG particles ranged from 0 to $0.75 \mathrm{wt} \%$. The rest of nanoparticles was added to DMF and stirred for $4 \mathrm{~h}$ at room temperature. The mixture was sonicated (Woson, China) at $50 \mathrm{kHz}$ for $3 \mathrm{~h}$ to ensure the homogeneous spread of the nanoparticles and break up the agglomerates. Then, CA (17.5 wt $\%$, by weight of the solution) was added to the initial mixture and dissolved in the solvent at $2000 \mathrm{rpm}$ for $15 \mathrm{~h}$. The casting solution was then degassed, overnight without stirring to remove the gas bubbles, completely. The solution was then cast onto a glass plate using automatic casting machine (Coa Test, Taiwan) to produce a flat sheet membrane (shear rate and thickness of $10 \mathrm{~mm} \mathrm{~s}^{-1}$ and $200 \mu \mathrm{m}$, respectively) via phase inversion method. The fabricated membranes were immersed in fresh distilled water for $24 \mathrm{~h}$ to remove all the 
residual solvent. The synthesized membranes were washed thoroughly with distilled water and kept in DI water to make them ready for further characterization.

\section{Membrane characterizations}

\section{SEM}

The morphology of the membrane samples was observed by a scanning electron microscope (LEO 1455VP, UK) operating at $15 \mathrm{kV}$. For cross-sectional micrographs, the membranes were fractured in liquid nitrogen. All the samples were gold-coated by sputtering to produce electrical conductivity.

\section{TEM}

TEM analysis was performed with a Philips CM120 transmission electron microscope operating at $120 \mathrm{keV}$. The sample membranes were embedded with epoxy, and cross sections of approximately $50 \mathrm{~nm}$ were obtained by sectioning with a Leica Ultracut UCT ultramicrotome.

\section{FTIR}

The chemical structure of nanoparticles was studied by Fourier transform infrared spectroscopy (FTIR) with a VERTEX 70 FTIR spectrometer (Bruker, Germany) in the range of $400-4000 \mathrm{~cm}^{-1}$. The sample pellet of nanoparticles for the FTIR test was prepared by mixing the particles with $\mathrm{KBr}$.

\section{Abrasion-resistance testing}

Abrasion is one of the most frequent wear mechanisms on materials surface. It is defined as the material pull-out caused by the action of hard particles on the material surface which is subjected to the abrasive wear due to the relative movement between two surfaces [43]. The abrasion resistance of pure and nanocomposite membranes was investigated by stirred cell equipped with a fixture to keep the membrane inside of abrasion suspension. Silicon carbide with 200-450 mesh (32-75 $\mu \mathrm{m})$ particle size obtained from Sigma-Aldrich was used as the abrasive particle suspended in DI water. To perform the abrasion test, $150 \mathrm{~g}$ of abrasive slurry containing $10 \mathrm{wt} \%$ silicon carbide dispersed in DI water was placed in a $200 \mathrm{~mL}$ beaker to allow sufficient movement of the slurry. The abrasion mixture was stirred at $400 \mathrm{rpm}$ for 20 days according to the literature. Subsequently, the membrane sample was washed under ultrasonication for $10 \mathrm{~min}$ to remove all debris worn away from the membrane surface. A detailed description of the abrasionresistance test has been given by Ji et al. [44] and Lai et al. [45]. The membrane samples were weighed before and after the abrasion to record the loss in mass due to the abrasive wearing. To carry out observatory analysis, SEM micrographs of the surface of the original and the abraded samples were taken with an LEO 1455VP SEM (UK) at an accelerating voltage of $10 \mathrm{kV}$.

\section{Membrane porosity}

The membrane porosity $\varepsilon(\%)$ can be defined as the volume of pores divided by the total volume of the porous membrane. The porosity of different membranes was calculated through Eq (8) [46, 47]:

$\varepsilon(\%)=\frac{\left(W_{\mathrm{w}}-W_{\mathrm{d}}\right) / D_{\mathrm{w}}}{\left(W_{\mathrm{w}}-W_{\mathrm{d}}\right) / D_{\mathrm{w}}+W_{\mathrm{d}} / D_{\mathrm{p}}} \times 100$

where $\varepsilon$ is the porosity of membrane (\%), $W_{\mathrm{w}}$ is the wet sample weight $(\mathrm{g}), W_{\mathrm{d}}$ is the dry sample weight $(\mathrm{g})$, and $D_{\mathrm{w}}$ $\left(0.998 \mathrm{~g} \mathrm{.cm}^{-3}\right)$ and $D_{\mathrm{p}}\left(1.3 \mathrm{~g} . \mathrm{cm}^{-3}\right)$ are the density of water (selected due to the hydrophilicity property of $\mathrm{CA}$ ) and polymer at $25^{\circ} \mathrm{C}$, respectively. Three samples were measured for each membrane and the average value of membrane porosity was reported.

\section{Contact angle measurement}

The hydrophilicity of the membrane was determined by measuring the contact angle of the membrane surface with a contact angle goniometer (PGX, Thwing-Albert Instrument Co., USA). At least five water contact angles at different locations on the membrane surface were recorded to get a reliable value.

\section{Water content}

Water content (WC) tests were conducted to study the adsorption of water to the membranes containing the ND and ND-COOH nanoparticles. Pieces of different membrane samples were immersed in DI water at room temperature for $24 \mathrm{~h}$ and the weight of wetted membrane $\left(W_{\text {wet }}\right)$ was measured after mopping with a filter paper. The dry weight $\left(W_{\text {dry }}\right)$ was determined after $48 \mathrm{~h}$ drying at $75^{\circ} \mathrm{C}$. The $W C$ ratio was calculated by the following equation $[48,49]$ :

$\mathrm{WC}(\%)=\frac{W_{\text {wet }}-W_{\text {dry }}}{W_{\text {wet }}} \times 100$.

\section{Mechanical properties}

Tensile strength was performed by a universal testing machine (STAM-D, Santam, Iran) at room temperature at a crosshead speed of $10 \mathrm{~mm} \mathrm{~min}^{-1}$. All samples for mechanical testing were rectangular. The tensile strength was 
extracted from the relevant stress-strain curves. The results were the average of at least three tests.

\section{TGA}

The Thermogravimetric analysis (TGA) of pristine and functionalized ND particles was determined using a thermogravimetric analyzer (Pyris Diamond TG/DTA, PerkinElmer, USA) at a heating rate of $10{ }^{\circ} \mathrm{C} \mathrm{min}{ }^{-1}$ from room temperature to $750{ }^{\circ} \mathrm{C}$.

\section{HA adsorption experiments}

Adsorption experiments were carried out by a batch method at ambient temperature. The pure $\mathrm{CA}$ and nanocomposite flat sheet membranes were cut in the size of $1 \times 1 \mathrm{~cm}^{2}$ and immersed into $5 \mathrm{~mL}$ of $100 \mathrm{mg} \mathrm{L}^{-1} \mathrm{HA}$ solution at $\mathrm{pH} 7$ (adjusted with $0.1 \mathrm{~N} \mathrm{HCl}$ solutions). Then, the samples containing adsorbed HA were removed from the basic solution. The vials were agitated with a shaker and the adsorption experiments were carried out at the temperature of $25^{\circ} \mathrm{C}$ for $24 \mathrm{~h}$ to reach equilibrium. The HA adsorptions were measured at room temperature using a UV spectrophotometer (Bio Quest CE2501). The adsorption capacity was calculated as follows [7, 50]:

HA adsorption capacity $=\frac{C_{0}-C}{A} \times V$

where $A\left(\mathrm{~m}^{2}\right)$ is the membrane area, $V$ is the total volume of the solution $(5 \mathrm{~mL})$, and $C_{0}$ and $C$ are the concentration of HA solution before and after contact with the membranes, respectively.

\section{Analyses of fouling resistances}

The effects of ND and ND-PEG nanoparticles on the removal efficiency of HA and the improvement of UF membrane fouling behavior were investigated. HA solution was prepared by dissolving $1 \mathrm{~g}$ of HA in $1 \mathrm{~L}$ of Milli-Q water. The solution $\mathrm{pH}$ was adjusted at 6 by adding a small amount of either $0.1 \mathrm{M} \mathrm{HCl}$ or $0.1 \mathrm{M} \mathrm{NaOH}$. The solution was filtered through a $0.45 \mu \mathrm{m}$ filter to remove particulates and stored in the refrigerator $\left(4{ }^{\circ} \mathrm{C}\right)$ before use. Experiments were performed in a dead-end filtration setup.

After pure water flux $\left(J_{\mathrm{w} 1}\right)$ tests, the prepared HA solution was performed and the permeate flux $\left(J_{\mathrm{HA}}\right)$ profile was recorded every $10 \mathrm{~min}$ to determine the dynamic fouling resistance of the membrane. After 240 min of HA filtration, the membrane was cleaned with distilled water under magnetic stirring for $30 \mathrm{~min}$, and then, pure water was again passed through the membrane to measure second pure water flux $\left(J_{\mathrm{w}_{2}}\right)$. The HA filtration measurement was carried out in transmembrane pressure of $1.5 \mathrm{bar}$. Three samples were performed for each experiment and the average value was reported. To evaluate the fouling resistance of the membranes, the flux recovery ratio (FRR) was calculated using the following equation [33]:

$\operatorname{FRR}(\%)=\frac{J_{\mathrm{w} 2}}{J_{\mathrm{w} 1}} \times 100$.

The flux loss caused by reversible (RFR), irreversible (IFR), and total fouling ratio (TFR) of the membrane in filtration was defined by the following equations [51]:

$\operatorname{RFR}(\%)=\left(\frac{J_{\mathrm{w} 2}-J_{\mathrm{HA}}}{J_{\mathrm{w} 1}}\right) \times 100$

$\operatorname{IFR}(\%)=\left(\frac{J_{\mathrm{w} 1}-J_{\mathrm{w} 2}}{J_{\mathrm{w} 1}}\right) \times 100$

$\operatorname{TFR}(\%)=\operatorname{RFR}(\%)+\operatorname{IFR}(\%)=\left(\frac{J_{\mathrm{w} 1}-J_{\mathrm{HA}}}{J_{\mathrm{w} 1}}\right) \times 100$.

To measure the membrane rejection, the HA concentrations of feed and permeate solutions were determined using a UV spectrophotometer (Bio Quest CE2501) and the HA rejection of membrane was calculated using Eq (15) as follows [52, 53]:

$R(\%)=\left(1-\frac{C_{\mathrm{p}}}{C_{\mathrm{f}}}\right) \times 100$

where $R$ is the membrane rejection, and $C_{\mathrm{p}}$ and $C_{\mathrm{f}}$ are permeate and feed concentrations, respectively.

\section{Results and discussion}

\section{Characteristics of functionalized ND nanoparticles}

Figure 1 indicates the FTIR spectra of the pristine ND, ND-COOH, and ND-PEG nanoparticles. For the ND powder, the main features in the spectrum are related to $\mathrm{C}-\mathrm{H}$ vibrations at 2981.7 and $2856.8 \mathrm{~cm}^{-1}$ that correspond to the asymmetric and symmetric $\mathrm{C}-\mathrm{H}$-stretching vibrations, respectively, and $\mathrm{O}-\mathrm{H}-$ bending vibrations at 3486.2 and $1642.3 \mathrm{~cm}^{-1}$. In addition, the spectrum revealed bonds at 1764.8 and $1177 \mathrm{~cm}^{-1}$ which are attributed to the stretching vibrations of carbonyl $(\mathrm{C}=\mathrm{O})$ and ether $(\mathrm{C}-\mathrm{O}-\mathrm{C})$ groups, respectively [54].

For the ND-COOH nanoparticles, it has almost the same IR adsorptions as those of pristine $\mathrm{ND}$, but $\mathrm{C}-\mathrm{H}$ bonds in ND completely disappear and the absorption peak of $\mathrm{C}=\mathrm{O}$ are shifted to $1798 \mathrm{~cm}^{-1}$ due to the conversion of some 


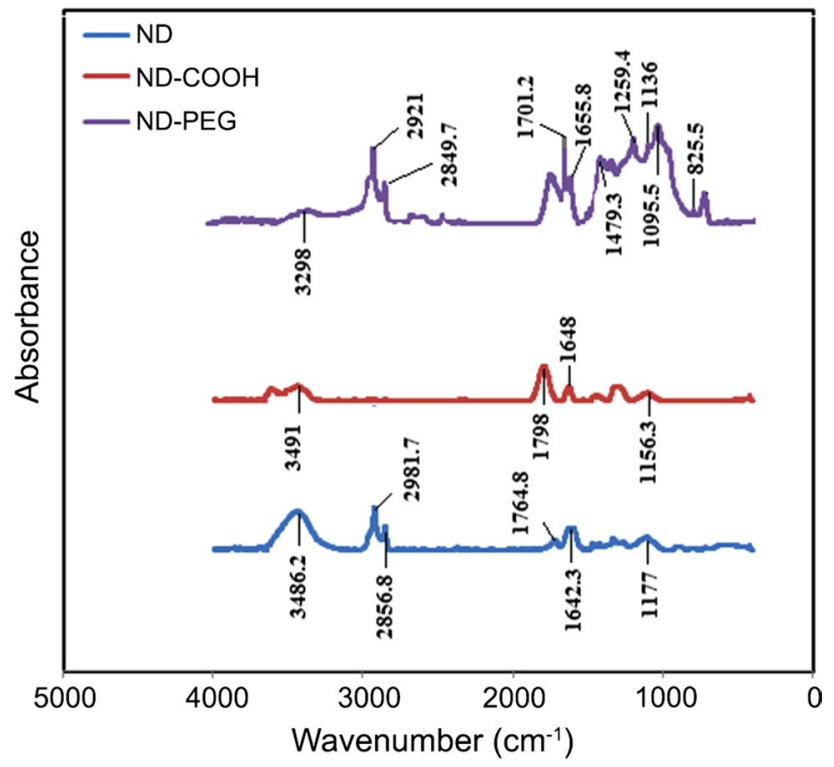

Fig. 1 FTIR spectra of pristine ND, ND-COOH, and ND-PEG nanoparticles

oxygen containing groups like ketone, alcohol, and ester to carboxylic group [55].

In the characteristic peaks of ND-PEG nanoparticles, $\mathrm{C}-\mathrm{H}$-stretching vibrations appeared at 2849.7 and $2921 \mathrm{~cm}^{-1}$ corresponding to the $-\mathrm{CH}_{3}$ in PEG molecules. In addition, other characteristic peaks of PEG chains at 1479.3, $1259.4,1136,1095.5$, and $825.5 \mathrm{~cm}^{-1}$ were all observed, indicating that PEG was indeed attached to the surface of ND nanoparticles [27]. However, the intensity of the peak at $1095.5 \mathrm{~cm}^{-1}$ significantly increased. This increase is attributed to the $\mathrm{C}-\mathrm{O}-\mathrm{C}$-stretching modes of ether groups in PEG molecules.

Figure 2 shows the TGA curves of the pristine ND, ND$\mathrm{COOH}$, and ND-PEG nanoparticles. The weight loss percentages of ND, ND-COOH, and ND-PEG nanoparticles are $1.22,3.67$, and $18.81 \%$ at $500{ }^{\circ} \mathrm{C}$, respectively, suggesting that more functional groups were introduced on the surface of ND during PEG-grafting steps. The major weight loss of ND-PEG nanoparticles occurred between 180 and $750{ }^{\circ} \mathrm{C}$. This weight loss may greatly be ascribed to the decomposition of the PEG chains, since the onset was close to the decomposition temperature of PEG $\left(177^{\circ} \mathrm{C}\right)$ [27].

\section{Membrane characterization}

\section{Mechanical properties}

The mechanical properties of pure and nanocomposite membrane samples were measured and the results are shown in Table 1. It can be seen that the tensile strength of the nanocomposite membranes increased with the increase of ND

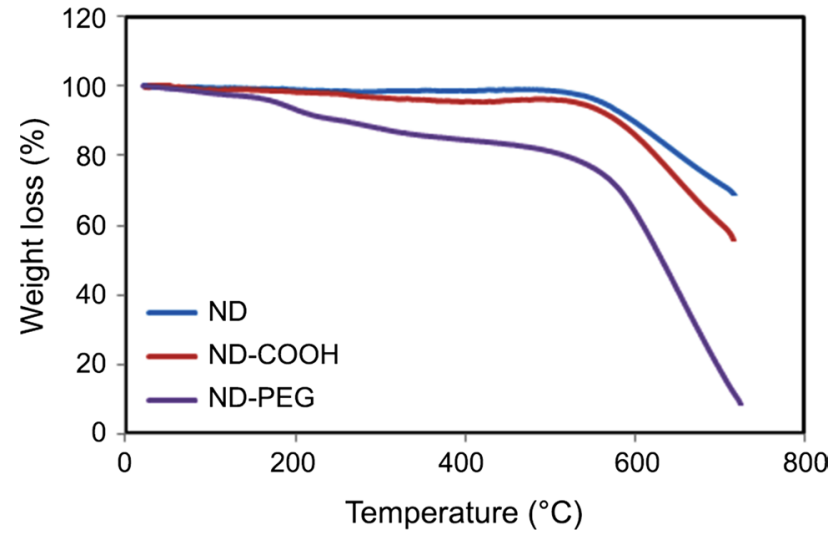

Fig. 2 TGA curves of pristine ND, ND-COOH, and ND-PEG nanoparticles

and ND-PEG nanoparticle concentration until $0.5 \mathrm{wt} \%$. Then, the tensile strength decreased by adding nanoparticles. The tensile strength increased by $54.6 \%$ in the sample with $0.5 \mathrm{wt} \%$ of ND-PEG nanoparticles. An increase in the tensile strength was observed for the CA/ND-PEG membrane in comparison with $\mathrm{CA} / \mathrm{ND}$ membrane, due to well dispersion of ND-PEG nanoparticles and well interaction between these nanoparticles and CA matrix.

However, the higher content of nanoparticles $(>0.5 \mathrm{wt} \%)$ will obviously cause a decrease in the mechanical properties of the nanocomposite membranes. When the content of ND and ND-PEG nanoparticles was $0.75 \mathrm{wt} \%$, the microstructure of membranes obviously changed due to the aggregation of nanoparticles in CA matrix and this will result in the decline of mechanical properties [56].

\section{Hydrophilicity, porosity, and water content of membranes}

The results of contact angle measurements for membranes are given in Table 1. The contact angle of neat CA membrane decreased from 65.4 to 58 and 52.2 by adding $0.5 \mathrm{wt} \%$ ND and ND-PEG nanoparticles, respectively. A decrease in the water contact angle was corresponded with the improvement in membrane hydrophilicity. In comparison with the CA/ND membrane, CA membranes containing $0.5 \mathrm{wt} \%$ of ND-PEG nanoparticles show the lowest amount of water contact angles. This is due to the existence of hydroxyl hydrophilic functional groups on the membranes structures as well as the good dispersion of ND-PEG nanoparticles. Any further increase in ND nanoparticles up to $0.75 \mathrm{wt} \%$ increased the water contact angle. According to the results reported by Xu et al., any increase in water contact angel at a higher ND nanoparticles content supports our speculation regarding the agglomeration and cluster formation of ND nanoparticles and consequently non-uniform dispersion of nanoparticles at higher concentrations [57]. 
Table 1 Tensile strength, water contact angles, water content (\%), porosity (\%), HA adsorption capacity, and weight loss per unit area for pure $\mathrm{CA}$ and its nanocomposite membranes

\begin{tabular}{lllllll}
\hline Sample code & $\begin{array}{l}\text { Tensile } \\
\text { strength (MPa) }\end{array}$ & $\begin{array}{l}\text { Water contact } \\
\text { angles }\left(^{\circ}\right)\end{array}$ & $\begin{array}{l}\text { Water con- } \\
\text { tent }(\%)\end{array}$ & porosity $(\varepsilon)(\%)$ & $\begin{array}{l}\text { HA adsorption } \\
\text { capacity }\left(\mathrm{mg} \mathrm{cm}^{-2}\right)\end{array}$ & $\begin{array}{l}\text { Weight loss } \\
\text { per unit area } \\
\left(\mathrm{mg} \mathrm{m}^{-2}\right)\end{array}$ \\
\hline CA & 9.7 & 65.4 & 71.6 & 76.7 & 2.85 & 7.2 \\
CA/ND $(0.25 \mathrm{wt} \%)$ & 10 & 60.3 & 74.2 & 78.6 & 2.83 & - \\
CA/ND $(0.5 \mathrm{wt} \%)$ & 10.4 & 58 & 75 & 80.5 & 2.7 & 4.3 \\
CA/ND (0.75 wt $\%)$ & 9 & 59.1 & 73.5 & 78.5 & 2.8 & - \\
CA/ND-PEG $(0.25 \mathrm{wt} \%)$ & 11.8 & 55.8 & 79.2 & 82.5 & 2.5 & - \\
CA/ND-PEG $(0.5 \mathrm{wt} \%)$ & 15 & 52.2 & 79.8 & 82.8 & 2.15 & - \\
CA/ND-PEG $(0.75 \mathrm{wt} \%)$ & 13.4 & 52.7 & 78.8 & 82.2 & 2.6 & - \\
\hline
\end{tabular}

The WC was calculated using Eq (9) and the value of the membranes are shown in Table 1. From Table 1, the WC of neat CA membrane showed a value of $71.6 \%$. It can be seen that all the nanocomposite membranes show higher WC value than neat CA. The highest value of 79.8\% was appeared when the content of ND-PEG nanoparticles reached $0.5 \mathrm{wt} \%$. The parameter of WC may be due to the detachment of polymer chains from the ND-PEG nanoparticles surface, causing interface voids. Furthermore, this led to an increase in void volume, resulting in the formation of bigger size pores on the membrane surface and an increase of $\mathrm{WC}$ in the pores.

The membrane porosities have been measured using gravimetric method and the results are reported in Table 1. It is clear that increasing the concentration of pure and functionalized ND nanoparticles increased the membrane porosity that attained its maximum value at the concentration of $0.5 \mathrm{wt} \%$. Any further increase in the ND content decreased the porosity, which would contribute to particles' agglomeration. However, mixing hydrophilic nanoparticles with CA polymer could enhance the volume fraction between polymer chains, in addition, causing fast exchange of solvent and non-solvent during the phase inversion process [58]. Moreover, during the phase inversion process of nanocomposite membranes, especially CA/ND-PEG (0.5 wt $\%)$, the solvent and the non-solvent exchange rate increased due to the hydrophilic nature and well dispersion of nanoparticles additive. This led to the formation of membrane with more porous surface.

\section{HA adsorption test}

Table 1 shows the results obtained from HA adsorption test. Pure CA membrane sheet showed the maximum HA adsorption about $2.85 \mathrm{mg} \mathrm{cm}^{-2}$. As the pristine ND particles concentration increased from 0 to $0.5 \mathrm{wt} \%$, the amounts of adsorbed HA decreased to $2.7 \mathrm{mg} \mathrm{cm}^{-2}$. However, as the ND content reached $0.75 \mathrm{wt} \%$ in the nanocomposite membrane, the amount of adsorbed HA increased from 2.7 to $2.8 \mathrm{mg} \mathrm{cm}^{-2}$, due to sever agglomeration of nanoparticles.

As shown in Table 1, by increasing the ND-PEG nanoparticles loading, the amount of adsorbed HA reached 2.5, 2.15, and $2.6 \mathrm{mg} \mathrm{cm}^{-2}$ for loading of $0.25,0.5$, and $0.75 \mathrm{wt} \%$, respectively. The reduction in HA adsorption on CA/NDPEG nanocomposite membranes (especially at $0.5 \mathrm{wt} \%$ ) was ascribed to hydrophilic and well dispersion properties of ND-PEG nanoparticles. In addition, due to the formation of thin water film on the surface of CA/ND-PEG nanocomposite membranes, the reduction in HA adsorption occurred $[7,50]$.

\section{Membrane morphology}

The top surface and cross-sectional SEM micrographs of CA membrane and the selected nanocomposite membranes are presented in Fig. 3. As evidenced from these SEMs, the porosity of membrane top surface increased due to the presence of both ND and ND-PEG nanoparticles.

The cross-sectional SEM micrographs in Fig. 4 show that all the membranes exhibit the typical asymmetric structure. It seems that macro-voids become longer when ND and NDPEG nanoparticles are added. The growth of macro-voids is determined by the relative diffusion rates between solvent and non-solvent. With the addition of ND and especially ND-PEG, the higher affinity between hydrophilic nanoparticles and water accelerates the exchange rate of solvent and non-solvent [59]. In the case of CA/ND-PEG (0.5 wt\%) membrane, the hydrophilic functional groups on ND-PEG nanoparticles may facilitate the exchange rate of solvent and non-solvent. These results indicated that the addition of ND and ND-PEG nanoparticles has bulky effects on the membrane structure formation.

Information about the dispersion of nanoparticles cannot be obtained from the SEM micrographs. Therefore, TEM was used to investigate the dispersion of nanoparticles in CA membranes, and the result is shown in Fig. 5. At low and especially high loading of ND nanoparticles, more 

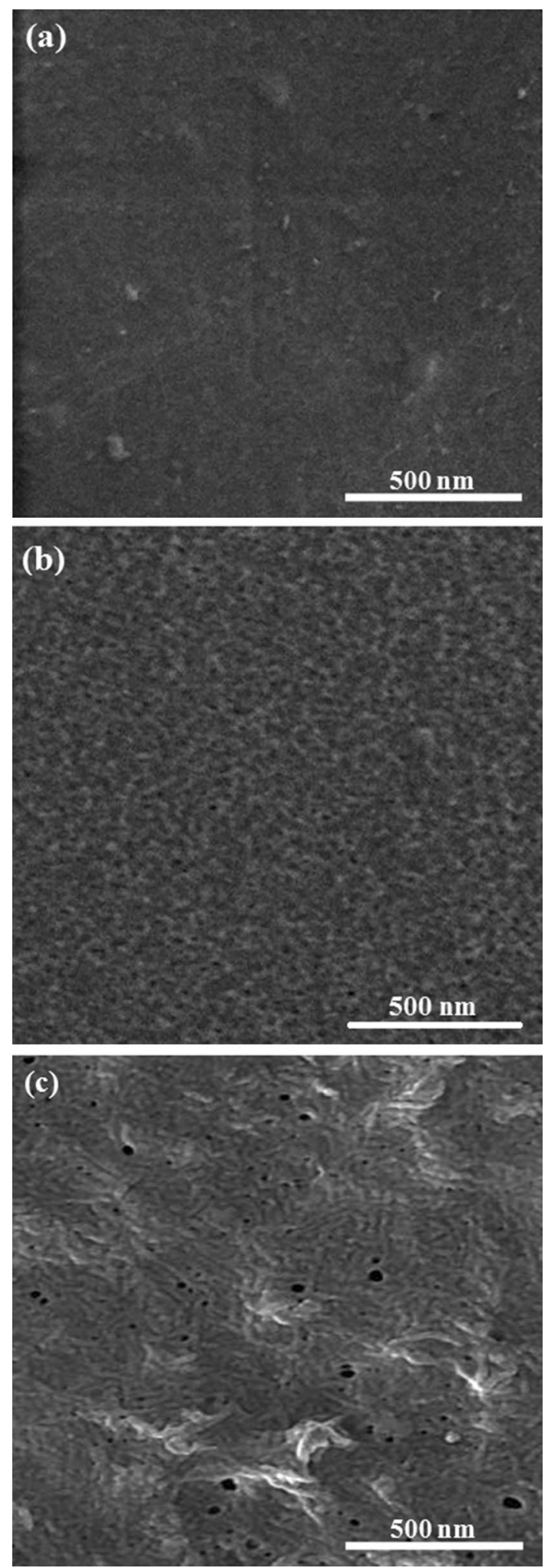

Fig. 3 SEM micrographs of top surface of: a CA, b CA/ND (0.5 wt \%), and c CA/ND-PEG (0.5 wt \%) membranes
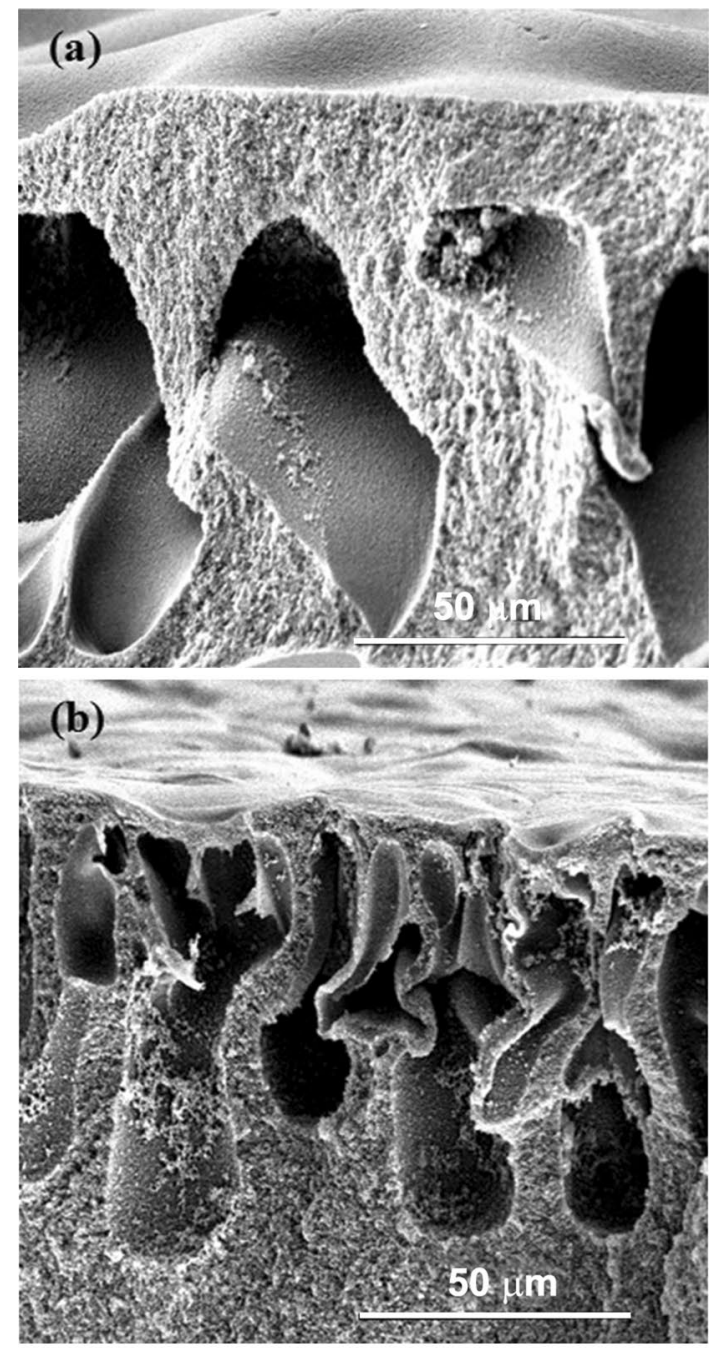

(c)

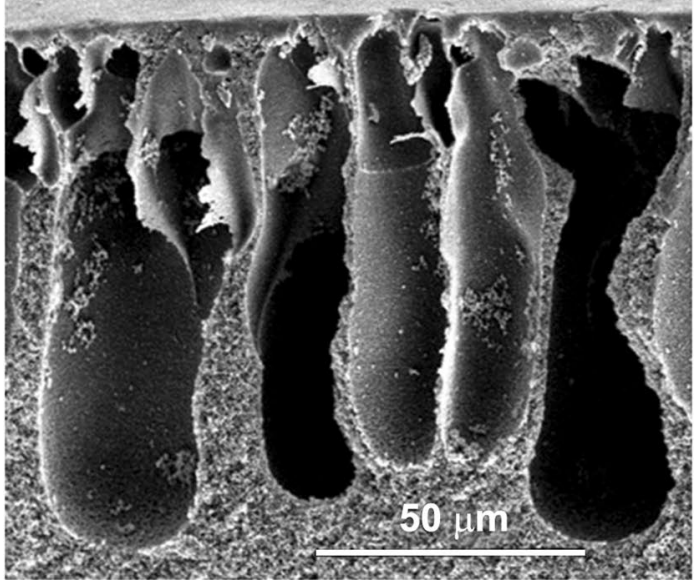

Fig. 4 SEM micrographs of the cross-sectional morphology of: a CA, b CA/ND (0.5 wt \%), and c CA/ND-PEG (0.5 wt\%) membranes 

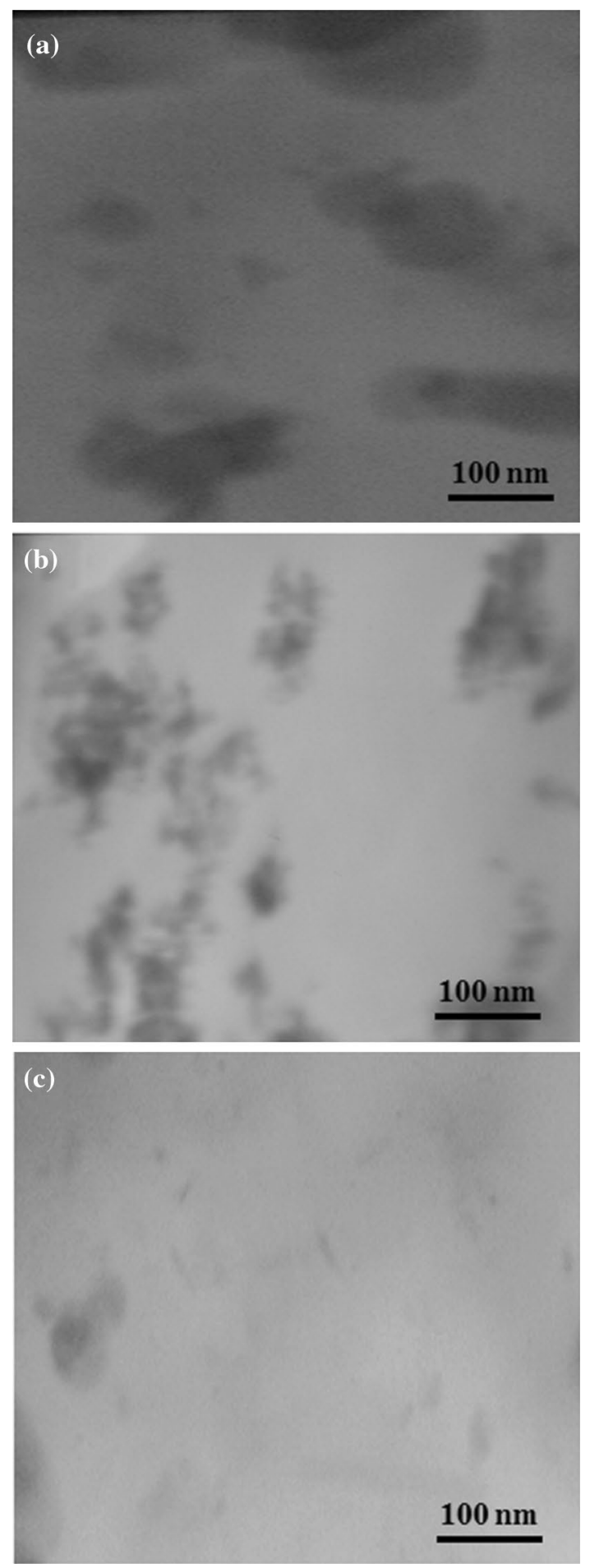

Fig. 5 TEM micrographs of distribution of: a $0.5 \mathrm{wt} \%$ of ND, b 0.75 wt $\%$ of ND, and c 0.5 wt \% of ND-PEG nanoparticles in CA membranes

agglomerations are formed (Fig. 5a, b). While, in lower amounts of functionalized nanoparticles, i.e., $0.5 \mathrm{wt} \% \mathrm{ND}-$ PEG, the construction of large aggregations was avoided, and therefore, a relatively uniform distribution of the
ND-PEG particles was established, as shown in Fig. 5c. In addition, this behavior has been reported elsewhere in which a smoother and rougher surface has been formed at low and high loading of nanoparticles into polymeric membranes, respectively [51,59].

\section{Abrasion resistance}

Table 1 represents the weight loss per unit area of pure CA and selected nanocomposite membranes after performing abrasion test. Obtained results show that in presence of NDPEG nanoparticles, the lowest weight loss is occurred. In the presence of pristine ND nanoparticles as nanofiller, the weight loss is still lower than that of the pure CA membrane. Interestingly, the CA/ND-PEG membrane shows superior performance and lower weight loss than both neat and nanocomposite CA membrane. This finding is mainly due to well distribution of ND nanoparticles as well as the contact reinforcement/matrix effect in the CA matrix. A similar result was reported by Lai [60], who showed that the abrasion resistance of poly(vinylidene fluoride) membrane increased by adding nanoclay as reinforcing agent. Specific wear rate $(W)$ can be calculated according to Ratner equation shown in Eq (16) as follows [61]:

$W=\frac{k \mu}{\sigma \varepsilon H}$

where $\mu$ is the coefficient of friction, $H$ is the indentation hardness, $\sigma$ is the tensile strength, $\varepsilon$ is the elongation at maximum load, and $k$ is a proportionality constant.

According to this equation and the results shown in Table 1, it is obvious that higher tensile strength as well as higher elongation-at-break results in lower abrasion rate. Therefore, CA/ND-PEG nanocomposite membrane with $0.5 \mathrm{wt} \%$ of ND nanoparticle content resists against the damage from the abrasive particles and exhibits lower abrasion rate due to the higher ductile strength. To better understand the effect of ND nanoparticles on the abrasion resistance of CA membrane, the abraded surfaces of the membranes were investigated by SEM analysis.

Figure 6 shows the abraded surfaces of neat $\mathrm{CA}$ and selected $\mathrm{CA} / \mathrm{ND}$ and $\mathrm{CA} / \mathrm{ND}-\mathrm{PEG}$ nanocomposite membranes. As shown in Fig. 6a, more ploughed furrows and pittings are formed on the abraded surface of CA membrane. By adding the ND nanoparticles, the number of pittings on the membrane surface remarkably decreases (Fig. 6b), implying that the presence of ND fillers in the nanocomposite membrane can enhance the abrasion resistance of CA membrane. Interestingly, in the presence of ND-PEG nanoparticles, the unenviable impact of abrasion test on the surface of the membrane was minimal and a smooth surface is observed (Fig. 6c). This result also implies that surface modification of ND nanoparticles can improve the interfacial 

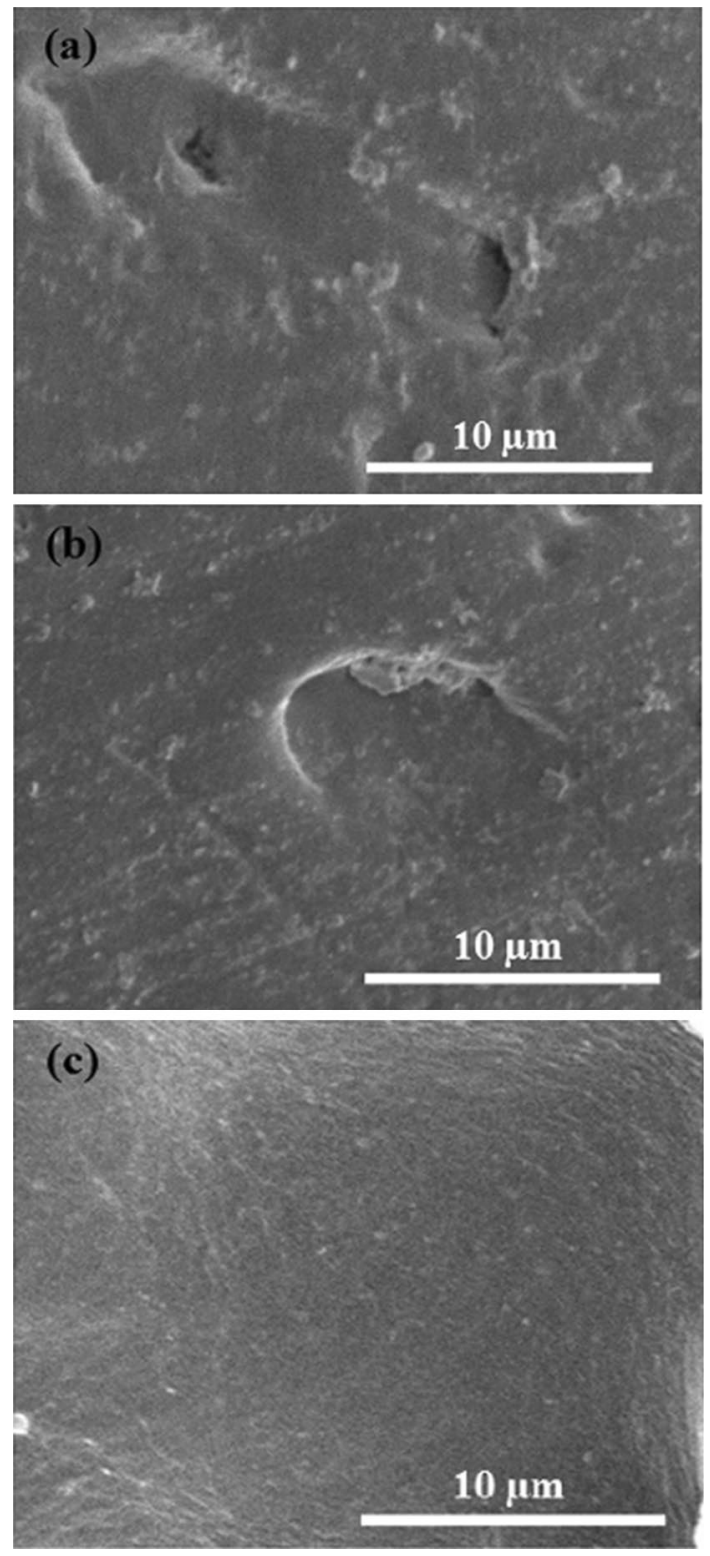

Fig. 6 SEM micrographs of membrane surface after the abrasion test: a CA, b CA/ND (0.5 wt \%) and c CA/ND-PEG (0.5 wt \%) membranes

bonding between ND-PEG nanoparticles and CA matrix, resulting in more uniform dispersion of ND particles in the bulk of polymer matrix (Fig. 5c) as well as on the surface of the CA membrane that improved the abrasion resistance of the nanocomposite membrane.

\section{Fouling analysis and membrane performance}

The flux decline behavior of the membrane during HA filtration is shown in Fig. 7. All filtration tests were carried out until the flux reaches a stable value. The permeation flux for CA/ND-PEG (0.5 wt $\%$ ) nanocomposite membrane was higher than that of the other membranes. It indicates

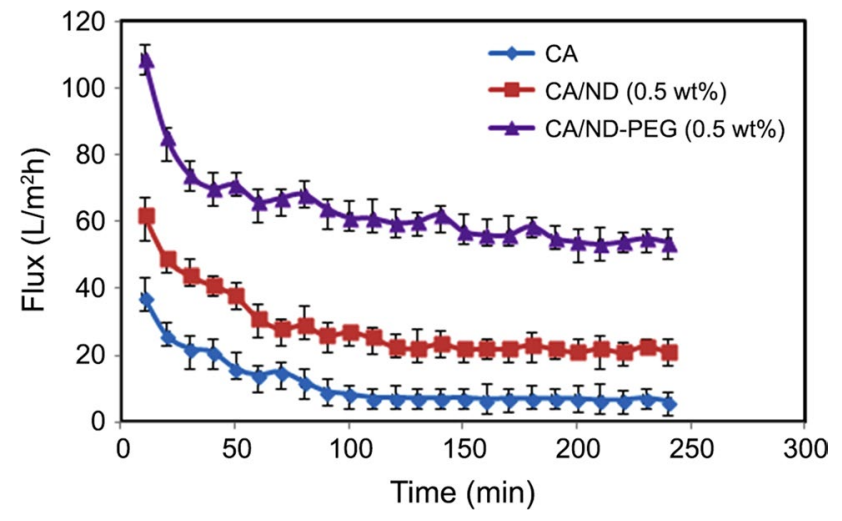

Fig. 7 Flux-time behavior of pure and nanocomposite membrane during filtration of $1 \mathrm{~g} \mathrm{~L}^{-1} \mathrm{HA}$ solution

that membrane hydrophilicity played the vital role in the improvement of HA filtration.

In an aqueous solution, the strong hydrogen bonding of water molecules to the oxygen atoms in PEG accumulates water molecules around PEG, which prevents hydrophobic foulants from approaching the surface. It is usually considered as a steric stabilization effect $[62,63]$. The characteristic features of the PEG coated layer on the ND nanoparticles, i.e., hydrophilicity, freedom of electrostatic charges, and the rapid motion of hydrated chains, have been of great help in terms of avoiding interaction between hydrophobic materials such as HA and the surface of ND nanoparticles. Therefore, ND-PEG nanoparticles improved the anti-fouling performance of CA membrane during HA filtration due to hydrophilicity, which prevents foulant attachments on the membrane surface.

Figure 8 illustrates the fitting of the obtained experimental data after using pure $\mathrm{CA}$ and $\mathrm{CA} / \mathrm{ND}-\mathrm{PEG}$ nanocomposite membranes at different predicted fouling mechanisms, including complete pore blocking, standard pore blocking, intermediate pore blocking, and cake formation. As shown in Fig. 8, it is observed that a cake filtration model provides the best fit for all membranes.

To evaluate the anti-fouling performance of the fabricated pure and nanocomposite $\mathrm{CA}$ membranes, flux recovery ratio (FRR), total fouling ratio (TFR), and reversible (RFR) and irreversible fouling ratio (IFR) were quantified during filtration experiments and the calculated values are presented in Table 2. It is obvious that the pure membrane had the highest TFR $(89.7 \%)$ and IFR (35\%) values. While in the CA/ ND-PEG (0.5 wt \%) membranes, TFR and IFR values were considerably reduced. In the case of modified membranes, the hydrophobic adsorption between the foulants and the surface of the modified membranes was decreased and the attached foulants were easily removed during filtration.

Since all membranes were tested under the same conditions, the surface property of membrane was a key factor in 

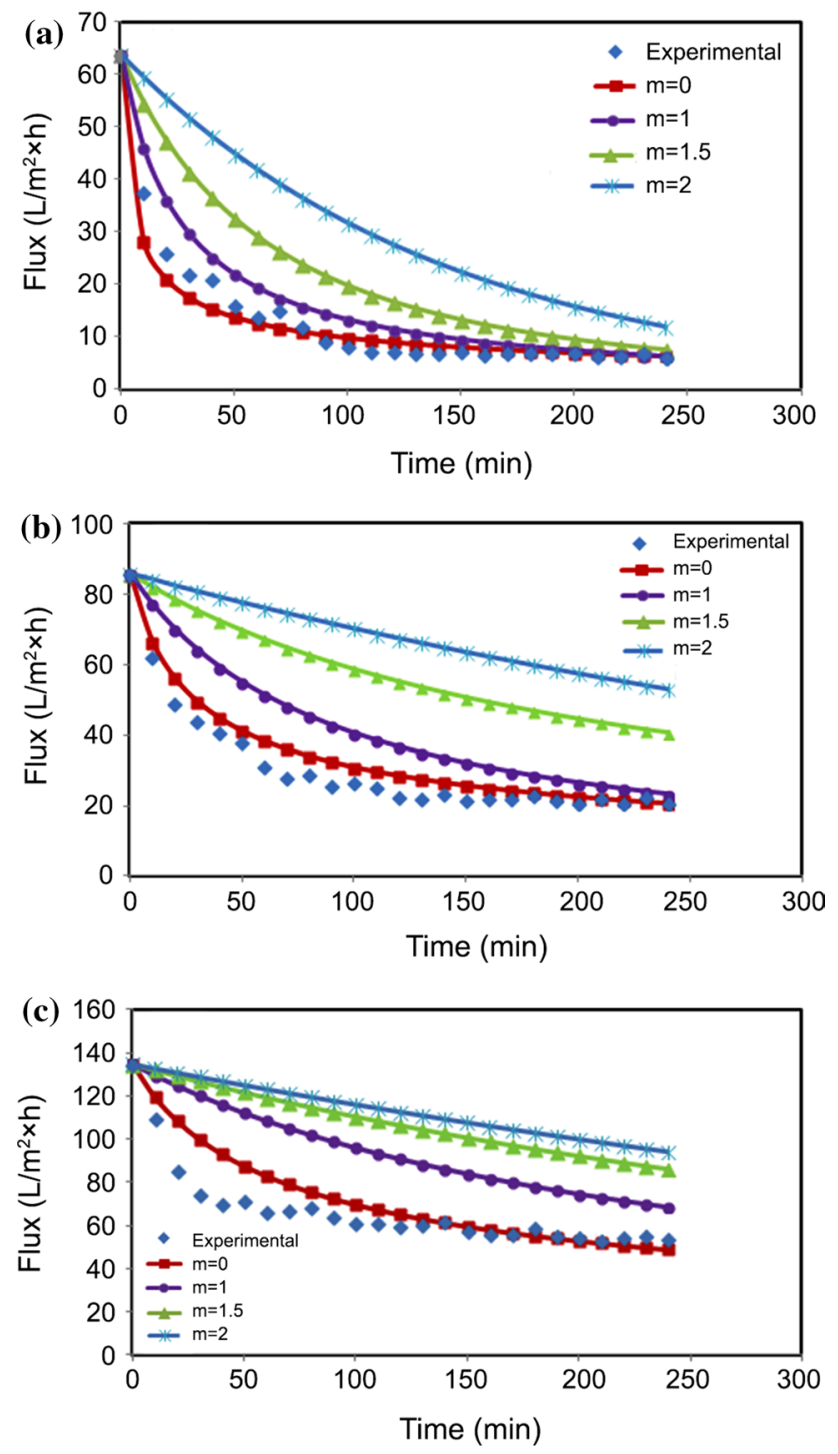

Fig. 8 Experimental data and Hermia fouling models for: a CA, b CA/ND (0.5 wt \%), and CA/ND-PEG (0.5 wt \%) membranes during filtration of HA solution

Table 2 Rejection and fouling parameters of the prepared membranes during HA filtration

\begin{tabular}{llllll}
\hline Sample code & RFR & IFR & TFR & FRR & Rejection \\
\hline CA & 54.7 & \multicolumn{1}{l}{35} & 89.7 & 65 & 94.5 \\
CA/ND $(0.5 \mathrm{wt} \%)$ & 54 & 20.4 & 74.4 & 80 & 94.8 \\
CA/ND-PEG $(0.5$ wt $\%)$ & 50.7 & 8.4 & 59.1 & 91.6 & 95.4 \\
\hline
\end{tabular}

determining the degree of TFR. Lower values of TFR show that less HA adsorption took place on the membrane surface or pore walls.

Performance studies to determine the rejection of HA solution showed that the presence of ND-PEG nanoparticles increased rejection compared with the membranes containing pristine ND particles (Table 2). The addition of ND-PEG nanoparticle created a more hydrophilic surface for the modified membranes that prevented HA molecules from settling closer to the surface of the membrane and thus increased the HA rejection.

\section{Conclusion}

Polyethylene glycol-grafted nanodiamond (ND-PEG) embedded cellulose acetate (CA) membranes were prepared through solution casting by phase inversion method. The anti-fouling behavior of pure and nanocomposite CA membranes during the filtration of humic acid (HA) was investigated. The results of FTIR revealed that the PEG molecules were formed on the surface of ND nanoparticles. SEM analyses of the surfaces of membranes depicted the increase in the number of pores by the addition of ND and especially ND-PEG nanoparticles into the polymer matrix. The results revealed that nanocomposite CA membrane containing $0.5 \mathrm{wt} \%$ PEGylated ND nanoparticles showed high hydrophilicity, high porosity, low HA adsorption capacity, high abrasion resistance, and excellent anti-fouling properties. It is due to the strong hydrogen bonding of water molecule to the oxygen atoms in PEG molecules, which prevents HA from approaching the surface of the membrane. According to the results obtained by Hermia's model, it was concluded that cake formation mechanism is the prevailing fouling mechanism, which can be occurred for neat and nanocomposite CA membranes. However, due to the enhancement of membrane wettability and surface hydrophilicity, CA/ND-PEG nanocomposite membrane showed more reversible fouling mechanism than that of the neat $\mathrm{CA}$ membrane. 
Acknowledgements The authors gratefully acknowledge financial support from Sahand University of Technology (Grant No. 30/15975).

Open Access This article is distributed under the terms of the Creative Commons Attribution 4.0 International License (http://creativecommons.org/licenses/by/4.0/), which permits unrestricted use, distribution, and reproduction in any medium, provided you give appropriate credit to the original author(s) and the source, provide a link to the Creative Commons license, and indicate if changes were made.

\section{References}

1. Dasgupta J, Chakraborty S, Sikder J, Kumar R, Pal D, Curcio S, Drioli E (2014) The effects of thermally stable titanium silicon oxide nanoparticles on structure and performance of cellulose acetate ultrafiltration membranes. Sep Purif Technol 133:55-68

2. Wei Y, Chu H, Dong B, Li X (2011) Evaluation of humic acid removal by a flat submerged membrane photoreactor. Chin Sci Bull 56:3437-3444

3. Szymański K, Morawski AW, Mozia S (2016) Humic acids removal in a photocatalytic membrane reactor with a ceramic UF membrane. Chem Eng J 305:19-27

4. Raghavendra SH, Arun MI, Ismail AF, Shilton SJ, Obaid A, Fun H-K (2015) Probing the morphology and antiorganic fouling behaviour of the polyetherimide membrane modified with hydrophilic organic acids as additives. New J Chem 39:6141-6150

5. Ghaemi N, Madaeni SS, Alizadeh A, Daraei P, Vatanpour V, Falsafi M (2012) Fabrication of cellulose acetate/sodium dodecyl sulfate nanofiltration membrane: characterization and performance in rejection of pesticides. Desalination 290:99-106

6. De Faria AF, De Moraes ACM, Andrade PF, Da Silva DS, do Carmo Gonçalves M, Alves OL (2017) Cellulose acetate membrane embedded with graphene oxide-silver nanocomposites and its ability to suppress microbial proliferation. Cellulose 24:781-796

7. Dehkordi FS, Pakizeh M, Namvar-Mahboub M (2015) Properties and ultrafiltration efficiency of cellulose acetate/organically modified $\mathrm{Mt}(\mathrm{CA} / \mathrm{OMMt})$ nanocomposite membrane for humic acid removal. Appl Clay Sci 105:178-185

8. Fu X, Maruyama T, Sotani T, Matsuyama H (2008) Effect of surface morphology on membrane fouling by humic acid with the use of cellulose acetate butyrate hollow fiber membranes. J Membr Sci 320:483-491

9. Kumar M, Gholamvand Z, Morrissey A, Nolan K, Ulbricht M, Lawler J (2016) Preparation and characterization of low fouling novel hybrid ultrafiltration membranes based on the blends of $\mathrm{GO}-\mathrm{TiO}_{2}$ nanocomposite and polysulfone for humic acid removal. J Membr Sci 506:38-49

10. Ye H, Zhang X, Zhao Z, Song B, Zhang Z, Song W (2017) Pervaporation performance of surface-modified zeolite/PU mixed matrix membranes for separation of phenol from water. Iran Polym J 26:193-203

11. Akbari A, Yegani R, Pourabbas B, Behboudi A (2016) Fabrication and study of fouling characteristics of HDPE/PEG grafted silica nanoparticles composite membrane for filtration of humic acid. Chem Eng Res Des 109:282-296

12. Etemadi H, Yegani R, Babaeipour V (2016) Study on the reinforcing effect of nanodiamond particles on the mechanical, thermal and antibacterial properties of cellulose acetate membranes. Diam Relat Mater 69:166-176

13. Krueger A (2008) The structure and reactivity of nanoscale diamond. J Mater Chem 18:1485-1492
14. Haleem YA, Liu D, Chen W, Wang C, Hong C, He Z, Liu J, Song $\mathrm{P}$, Yu S, Song L (2015) Surface functionalization and structure characterizations of nanodiamond and its epoxy based nanocomposites. Compos Part B Eng 78:480-487

15. Zhu Y, Xu X, Wang B, Feng Z (2004) Surface modification and dispersion of nanodiamond in clean oil. Chin Particuol 2:132-134

16. Huang TS, Tzeng Y, Liu YK, Chen YC, Walker KR, Guntupalli R, Liu C (2004) Immobilization of antibodies and bacterial binding on nanodiamond and carbon nanotubes for biosensor applications. Diam Relat Mater 13:1098-1102

17. Medina O, Nocua J, Mendoza F, Gomez-Moreno R, Avalos J, Rodriguez C, Morell G (2012) Bactericide and bacterial antiadhesive properties of the nanocrystalline diamond surface. Diam Relat Mater 22:77-81

18. Wehling J, Dringen R, Zare RN, Maas M, Rezwan K (2014) Bactericidal activity of partially oxidized nanodiamonds. ACS Nano 8:6475-6483

19. Mochalin VN, Shenderova O, Ho D, Gogotsi Y (2012) The properties and applications of nanodiamonds. Nat Nanotech 7:11-23

20. Burns NA, Naclerio MA, Khan SA, Shojaei A, Raghavan SR (2014) Nanodiamond gels in nonpolar media: colloidal and rheological properties. J Rheol 58:1599-1614

21. Holt KB (2007) Diamond at the nanoscale: applications of diamond nanoparticles from cellular biomarkers to quantum computing. Philos Trans A Math Phys Eng Sci 365:2845-2861

22. Li C-C, Huang C-L (2010) Preparation of clear colloidal solutions of detonation nanodiamond in organic solvents. Coll Surf A 353:52-56

23. Mykhaylyk OO, Solonin YM, Batchelder DN, Brydson R (2005) Transformation of nanodiamond into carbon onions: a comparative study by high-resolution transmission electron microscopy, electron energy-loss spectroscopy, X-ray diffraction, smallangle X-ray scattering, and ultraviolet Raman spectroscopy. J Appl Phys 97:074302. https://doi.org/10.1063/1.1868054

24. Wang D, Tong Y, Li Y, Tian Z, Cao R, Yang B (2013) PEGylated nanodiamond for chemotherapeutic drug delivery. Diam Relat Mater 36:26-34

25. Lee JW, Lee S, Jang S, Han KY, Kim Y, Hyun J, Kim SK, Lee Y (2013) Preparation of non-aggregated fluorescent nanodiamonds (FNDs) by non-covalent coating with a block copolymer and proteins for enhancement of intracellular uptake. Mol BioSyst 9:1004-1011

26. Gol RM, Bera A, Banjo S, Ganguly B, Jewrajka SK (2014) Effect of amine spacer of PEG on the properties, performance and antifouling behavior of poly(piperazineamide) thin film composite nanofiltration membranes prepared by in situ PEGylation approach. J Membr Sci 472:154-166

27. Zhang X, Fu C, Feng L, Ji Y, Tao L, Huang Q, Li S, Wei Y (2012) PEGylation and polyPEGylation of nanodiamond. Polymer 53:3178-3184

28. Zhang S, Qiu G, Ting YP, Chung T-S (2013) Silver-PEGylated dendrimer nanocomposite coating for anti-fouling thin film composite membranes for water treatment. Coll Surf A 436:207-214

29. Mansourpanah Y, Shahebrahimi H, Kolvari E (2015) PEG-modified GO nanosheets, a desired additive to increase the rejection and antifouling characteristics of polyamide thin layer membranes. Chem Eng Res Des 104:530-540

30. Lin J, Ye W, Zhong K, Shen J, Jullok N, Sotto A, Van der Bruggen B (2016) Enhancement of polyethersulfone (PES) membrane doped by monodisperse Stöber silica for water treatment. Chem Eng Process 107:194-205

31. Shawky HA, Chae S-R, Lin S, Wiesner MR (2011) Synthesis and characterization of a carbon nanotube/polymer nanocomposite membrane for water treatment. Desalination 272:46-50

32. Teow YH, Ahmad AL, Lim JK, Ooi BS (2013) Studies on the surface properties of mixed-matrix membrane and its 
antifouling properties for humic acid removal. J Appl Polym Sci 128:3184-3192

33. Etemadi H, Yegani R, Babaeipour V (2017) Performance evaluation and antifouling analyses of cellulose acetate/nanodiamond nanocomposite membranes in water treatment. J Appl Polym Sci. https://doi.org/10.1002/app.44873

34. Etemadi H, Yegani R, Seyfollahi M (2017) The effect of amino functionalized and polyethylene glycol grafted nanodiamond on anti-biofouling properties of cellulose acetate membrane in membrane bioreactor systems. Sep Purif Technol 177:350-362

35. Charfi A, Ben Amar N, Harmand J (2012) Analysis of fouling mechanisms in anaerobic membrane bioreactors. Water Res 46:2637-2650

36. Rai C, Rai P, Majumdar G, De S, DasGupta S (2010) Mechanism of permeate flux decline during microfiltration of watermelon (Citrullus lanatus) juice. Food Bioprocess Technol 3:545-553

37. Bowen WR, Calvo JI, Hernandez A (1995) Steps of membrane blocking in flux decline during protein microfiltration. J Membr Sci 101:153-165

38. Córdova A, Astudillo C, Guerrero C, Vera C, Illanes A (2016) Assessment of the fouling mechanisms of an ultrafiltration membrane bioreactor during synthesis of galacto-oligosaccharides: effect of the operational variables. Desalination 393:79-89

39. Zhang W, Ding L (2015) Investigation of membrane fouling mechanisms using blocking models in the case of shear-enhanced ultrafiltration. Sep Purif Technol 141:160-169

40. Todisco S, Pena L, Drioli E, Tallarico P (1996) Analysis of the fouling mechanism in microfiltration of orange juice. J Food Process Preserv 20:453-466

41. Su W, Chen C, Zhu Y, Yang W, Dai H (2015) Fouling characteristics of dissolved organic matter in papermaking process water on polyethersulfone ultrafiltration membranes. BioResources 10:5906-5919

42. Teow YH, Ooi BS, Ahmad AL (2017) Fouling behaviours of PVDF-TiO ${ }_{2}$ mixed-matrix membrane applied to humic acid treatment. J Water Process Eng 15:89-98

43. Ibáñez MJ, Gilabert J, Vicent M, Gómez P, Muñoz D (2009) Determination of the wear resistance of traditional ceramic materials by means of micro-abrasion technique. Wear 267:2048-2054

44. Ji J, Zhou S, Lai CY, Wang B, Li K (2015) PVDF/palygorskite composite ultrafiltration membranes with enhanced abrasion resistance and flux. J Membr Sci 495:91-100

45. Lai CY, Groth A, Gray S, Duke M (2014) Enhanced abrasion resistant PVDF/nanoclay hollow fibre composite membranes for water treatment. J Membr Sci 449:146-157

46. Zhang M, Field RW, Zhang K (2014) Biogenic silver nanocomposite polyethersulfone UF membranes with antifouling properties. J Membr Sci 471:274-284

47. Andrade PF, de Faria AF, Quites FJ, Oliveira SR, Alves OL, Arruda MAZ, Gonçalves MC (2015) Inhibition of bacterial adhesion on cellulose acetate membranes containing silver nanoparticles. Cellulose 22:3895-3906

48. Sivakumar M, Mohanasundaram AK, Mohan D, Balu K, Rangarajan R (1998) Modification of cellulose acetate: its characterization and application as an ultrafiltration membrane. J Appl Polym Sci 67:1939-1946
49. Mehwish N, Kausar A, Siddiq M (2015) High-performance polyvinylidene fluoride/poly (styrene-butadiene-styrene)/functionalized MWCNTs-SCN-Ag nanocomposite membranes. Iran Polym J 24:549-559

50. Hwang L-L, Tseng H-H, Chen J-C (2011) Fabrication of polyphenylsulfone/polyetherimide blend membranes for ultrafiltration applications: the effects of blending ratio on membrane properties and humic acid removal performance. J Membr Sci 384:72-81

51. Khalid A, Al-Juhani AA, Al-Hamouz OC, Laoui T, Khan Z, Atieh MA (2015) Preparation and properties of nanocomposite polysulfone/multi-walled carbon nanotubes membranes for desalination. Desalination 367:134-144

52. Pouresmaeel-Selakjani P, Jahanshahi M, Peyravi M (2017) Synthesis of cellulose/silica nanocomposite through electrostatic interaction to reinforce polysulfone membranes. Cellulose 24:1333-1353

53. Liu H, Xiao C, Huang Q, Fan Z, Hu X, Shu W (2015) Study on interface structure and performance of homogeneous-reinforced polyvinyl chloride hollow fiber membranes. Iran Polym J 24:491-503

54. Lee J-Y, Lim D-P, Lim D-S (2007) Tribological behavior of PTFE nanocomposite films reinforced with carbon nanoparticles. Compos Part B Eng 38:810-816

55. Aris A, Shojaei A, Bagheri R (2015) Cure kinetics of nanodiamond-filled epoxy resin: influence of nanodiamond surface functionality. Ind Eng Chem Res 54:8954-8962

56. Liu D, Geng L, Fu Y, Dai X, Lü C (2011) Novel nanocomposite membranes based on sulfonated mesoporous silica nanoparticles modified sulfonated polyimides for direct methanol fuel cells. J Membr Sci 366:251-257

57. Xu Z, Zhang J, Shan M, Li Y, Li B, Niu J, Zhou B, Qian X (2014) Organosilane-functionalized graphene oxide for enhanced antifouling and mechanical properties of polyvinylidene fluoride ultrafiltration membranes. J Membr Sci 458:1-13

58. Zhang G, Lu S, Zhang L, Meng Q, Shen C, Zhang J (2014) Novel polysulfone hybrid ultrafiltration membrane prepared with $\mathrm{TiO}_{2}$-g-HEMA and its antifouling characteristics. J Membr Sci 436:163-173

59. Zhao S, Wang P, Wang C, Sun X, Zhang L (2012) Thermostable $\mathrm{PPESK} / \mathrm{TiO}_{2}$ nanocomposite ultrafiltration membrane for high temperature condensed water treatment. Desalination 299:35-43

60. Lai CY, Groth A, Gray S, Duke M (2014) Preparation and characterization of poly(vinylidene fluoride)/nanoclay nanocomposite flat sheet membranes for abrasion resistance. Water Res 57:56-66

61. Ratner SB, Farberova II, Radyukevich OV, Lure EG (1964) Connection between wear resistance of plastics and other mechanical properties. Sov Plast 12:37-45

62. Abe K, Higashi K, Watabe K, Kobayashi A, Limwikrant W, Yamamoto K, Moribe K (2015) Effects of the PEG molecular weight of a PEG-lipid and cholesterol on PEG chain flexibility on liposome surfaces. Colloids Surf A 474:63-70

63. Akbari A, Yegani R, Pourabbas B (2015) Synthesis of poly (ethylene glycol)(PEG) grafted silica nanoparticles with a minimum adhesion of proteins via one-pot one-step method. Colloids Surf A 484:206-215 